\title{
Erratum: A rare variant in APOC3 is associated with plasma triglyceride and VLDL levels in Europeans
}

Nicholas J. Timpson, Klaudia Walter, Josine L. Min, Ioanna Tachmazidou, Giovanni Malerba, So-Youn Shin, Lu Chen, Marta Futema, Lorraine Southam, Valentina lotchkova, Massimiliano Cocca, Jie Huang, Yasin Memari, Shane McCarthy, Petr Danecek, Dawn Muddyman, Massimo Mangino, Cristina Menni, John R.B. Perry, Susan M. Ring, Amadou Gaye, George Dedoussis, Aliki-Eleni Farmaki, Paul Burton, Philippa J. Talmud, Giovanni Gambaro, Tim D. Spector, George Davey Smith, Richard Durbin, J. Brent Richards, Steve E. Humphries, Eleftheria Zeggini, Nicole Soranzo \& UK10K Consortium

Nature Communications 5:4871 doi: 10.1038/ncomms5871 (2015); Published 16 Sep 2014; Updated 12 May 2015

During the production of this Article, errors were introduced in the frequencies of the variants rs964184-C and rs66505542-T reported in the Results section. The correct frequencies are 13 and $14 \%$, respectively. 